\title{
Improving the Cycle Life of a High-Rate, High-Potential Aqueous Dual-Ion Battery using Hyper-Dendritic Zinc and Copper Hexacyanoferrate
}

Tanya Gupta ${ }^{1}$, Andrew Kim ${ }^{1}$, Satyajit Phadke ${ }^{1}$, Shaurjo Biswas ${ }^{1}$, Thao Luong ${ }^{2}$, Benjamin Hertzberg ${ }^{1}$, Mylad Chamoun $^{3}$, Kenneth Evans-Lutterodt ${ }^{3}$, Daniel A. Steingart*1

${ }^{1}$ Department of Mechanical and Aerospace Engineering and the Andlinger Center for Energy and The Environment, Princeton University, NJ, 08544, USA

${ }^{2}$ University of California, Los Angeles, CA 90095, USA

${ }^{3}$ Brookhaven National Laboratory, Upton, New York, 11973, USA

Corresponding Author: *email: steingart@ princeton.edu,Ph.: (609) 258-1257, Fax: (609) 258-6109, Address: Room D428, Engineering Quadrangle, Olden St., Princeton, NJ, USA. 08544-5263 


\begin{abstract}
Prussian Blue Analogue (PBA)-Zn aqueous batteries are attractive because of the high potential of PBA against $\mathrm{Zn}(\sim 1.7 \mathrm{~V})$, relative safety of the system, and high rate capability. But, despite the long cycle life of PBA half-cells, full PBA-Zn battery systems studied thus far have typically reported only up to 100 cycles and suffer significant capacity fade beyond that. In this work we demonstrate that the loss in capacity retention and cycle life is a combined effect of $\mathrm{Zn}^{2+}$ ion poisoning at the PBA cathode, as well as dendrite formation in the zinc anode. We address both these issues via the use of a dual ion $\left(\mathrm{Na}^{+}\right.$as the primary charge carrier) electrolyte and hyper-dendritic Zinc (HD Zn) as the anode. The copper hexacyanoferrate (CuHcf) vs. HD Zn system with $\mathrm{Na}^{+}$ion electrolyte demonstrated herein exhibits $90 \%(83 \%)$ capacity retention after $300(500)$ cycles at a $5 \mathrm{C}$ rate and a $3 \%$ reduction in usable capacity from 1C to 5C. Detailed characterization is done using in situ synchrotron energy-dispersive XRD (EDXRD), conventional XRD, XPS, SEM, TEM, and electrochemical techniques.
\end{abstract}

\title{
Graphical Abstract
}

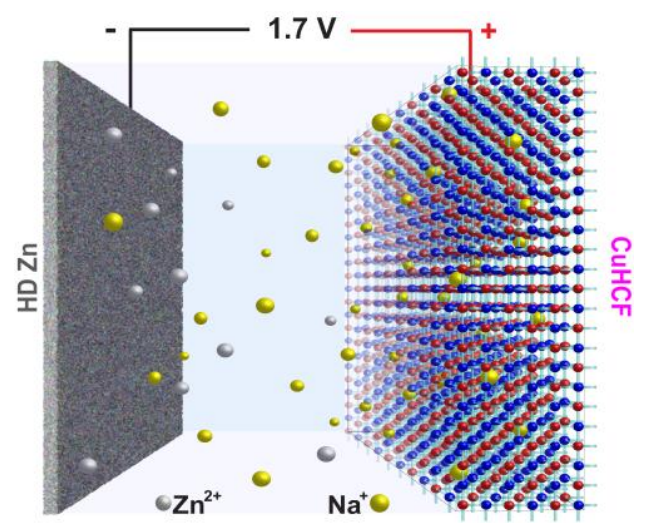

\section{Keywords}

Prussian blue analogue; hyper-dendritic zinc; in situ EDXRD; aqueous dual ion battery; high capacity retention; long battery cycle life 


\section{Background and Motivation}

Prussian blue $(\mathrm{PB})$ analogue electrodes have gained considerable attention due to their low cost, long cycle life and exceptional rate capability. The open cage-like structure allows for rapid intercalation/ deintercalation of various cations without significant change to the crystal structure [1-5]. The long cycle life, fast kinetics, and relative safety makes them suitable candidates for grid scale energy storage as well as wearable, flexible electronics. Several attempts have been made to build a complete battery using these electrodes. Wessels et al. [6] demonstrated Ni-Cu PB analogues for both electrodes and tuned the potential between the working and counter electrodes by changing the Ni:Cu ratio, although the maximum potential difference achieved was relatively low, of the order $0.4 \mathrm{~V}$. The Cui group [7] used activated carbon/polypyrrole hybrid electrodes vs. PBA to achieve an OCV of 1.2 V, albeit with the downside of specific energy of $5 \mathrm{Wh} \mathrm{kg}^{-1}$ at a rate of $20 \mathrm{C}$.

A recent development in Prussian blue analogues (PBAs) is the use of $\mathrm{Zn}$ as counter electrode. Zinc, like PBA, is low cost and relatively benign. More importantly, PBAs have a high potential $(\sim 1.7 \mathrm{~V})$ vs. $\mathrm{Zn}$ in aqueous electrolyte. In addition, this couple exhibits high energy and fast kinetics making it suitable for high power applications for grid scale frequency regulation and peak shaving applications, markets where California has demanded the installation of $1.3 \mathrm{GW}$ of power handling between 10 and 30 minutes duration in the next decade. Zhang et al. [8] demonstrated reversible cycling of $\mathrm{Zn}^{2+}$ ions in zinc hexacyanoferrate ( $\mathrm{ZnHcf}$ ) cathodes and $\mathrm{Zn}$ anodes. However, cycling $\mathrm{Zn}^{2+}$ in $\mathrm{ZnHcf}$ exhibits a low capacity retention of $81 \%$ after 100 cycles [8]. Cycling of $\mathrm{Zn}^{2+}$ in copper hexacyanoferrate (CuHcf) has also been investigated $[9,10]$. It was demonstrated that $\mathrm{Zn}^{2+}$ ions in CuHcf cathodes show $96.3 \%$ capacity retention for 100 cycles at $\mathrm{pH} 6$ [10]. But, as shown later, when these experiments were repeated in our lab, we observed a drastic degradation in capacity immediately after an equivalent of 100 cycles for an identical battery system. The fade rate suggests that repeated removal 
and insertion of $\mathrm{Zn}^{2+}$ ions irreversibly damages the crystal structure of $\mathrm{ZnHcf}$ or CuHcf eventually. Moreover, the maximum specific capacity of CuHcf cells has been found to be $60 \mathrm{mAh} \mathrm{g}^{-1}$ [11], regardless of the valency of the intercalating ion. This may seem counterintuitive, as one may expect the capacity of the battery to scale with increasing ionic charge. However, for mass loadings typical of CuHcf electrodes reported thus far, the concentration of ions in the electrolyte far exceed the available sites in the PBA crystal structure. To maintain charge balance, the number of sites occupied by the intercalating species will depend on the number of $\mathrm{Fe}^{2+}$ available for oxidation in the PBA crystal, which is the primary mechanism of storage $[12,13]$. This implies that it is the number of $\mathrm{Fe}^{2+}$ in the crystal structure that limits the cell capacity. Hence, the capacity of a CuHcf battery is insensitive to the ionic valency of the intercalating species, provided that its concentration in the electrolyte exceeds the moles of active material.

Thus, using $\mathrm{Zn}^{2+}$ as the intercalating species has no inherent advantage, in terms of specific capacity, over monovalent ions. In fact, a rather short cycle life and sharp capacity fade is seen in systems with $\mathrm{Zn}^{2+}$ ions and $\mathrm{Zn}$ anode $[8,10]$. We believe this behavior can be attributed to two major factors: $i$ ) cyclability of $\mathrm{Zn}^{2+}$ ions in PBA is not as reversible as other highly studied ions like $\mathrm{Na}^{+}, \mathrm{K}^{+}$, as it has been shown in the past $[11,14]$ that chemical stability of PBAs is highly sensitive to the intercalating ion; and ii) passivation of $\mathrm{Zn}$ and formation of $\mathrm{Zn}$ dendrites leads to slow degradation in capacity.

In this work, we demonstrate a battery framework that systematically addresses both these factors and exhibits exceptional performance when compared to previously known PBA-Zn systems. CuHcf is preferentially used as the cathode in our experiments over ZnHcf, since it has been extensively studied and is known to be stable over extended cycle times [13]. Additionally, hyper-dendritic zinc (HD Zn) is used as the anode to replace the conventional sheet $\mathrm{Zn}$, and a $1 \mathrm{M} \mathrm{Na}_{2} \mathrm{SO}_{4} / 0.01 \mathrm{M} \mathrm{H}_{2} \mathrm{SO}_{4}$ solution 
acts as the aqueous electrolyte. HD $\mathrm{Zn}$ is shown here to improve the performance of the $\mathrm{Zn}$ electrode, which otherwise forms dendrites [15-19] and limits the cycle life of the system. Detailed characterization of the active materials of the battery system is done using in situ synchrotron energydispersive X-ray diffraction (EDXRD), conventional XRD, SEM, TEM, XPS and various electrochemical techniques. Effect of aging on the extent of zinc poisoning is included in the Supplemental Information.

\section{Experimental Methods}

Copper Hexacyanoferrate (CuHcf) Electrode: The synthesis of CuHcf and subsequent fabrication of the slurry electrode is done by the same process as described elsewhere [13]. Briefly, $100 \mathrm{ml}$ of $0.1 \mathrm{M}$ copper nitrate and $100 \mathrm{ml}$ of $0.05 \mathrm{M}$ potassium hexacyanoferrate (III) were simultaneously added drop wise to $50 \mathrm{ml}$ of deionized water, while it was continuously stirred. Immediate precipitation of CuHcf particles is observed. The resulting suspension is sonicated for 20 minutes and allowed to rest overnight. It is then washed with water to remove residual reactants and filtered to obtain a greenishyellow powder of CuHcf. Detailed characterization of CuHcf particles has been done previously [13]. Slurry electrodes are used, as they enable higher mass loadings. The mass loading of the active material was $\sim 4 \mathrm{mg} \mathrm{cm}^{-2}$. Active material, carbon black, graphite, and polystyrene binder are mixed in a 1.5:1:1:0.5 weight ratio to form a slurry. It should be noted that a trace amount $(\sim 5 \mu 1)$ of the surfactant Triton x100 is added to $4 \mathrm{~g}$ of the slurry to wet the substrate (carbon cloth) effectively. The SEM images (Figure $1 \mathbf{d}$ ) of the slurry on carbon cloth show the wetting of the substrate, which is found to be better upon addition of the surfactant.

Hyper Dendritic Zinc (HD Zn) Electrode: For the anode, HD zinc is electroplated on a sheet of $\mathrm{Zn}$ metal (McMaster-Carr) in a $8.9 \mathrm{M} \mathrm{KOH} / 0.61 \mathrm{M} \mathrm{ZnO}$ electrolyte at $-2.0 \mathrm{~V}$ vs. $\mathrm{Hg} / \mathrm{HgO}$ [20]. Nickel is 
used as a counter electrode. The $\mathrm{HD}$ zinc electrode is washed in water and then in $0.01 \mathrm{M} \mathrm{H}_{2} \mathrm{SO}_{4}$ to reduce the zinc oxide layer formed, and to neutralize any residual $\mathrm{KOH}$ from the electrolyte. Figure 8 a shows the morphology of the HD Zn used in this study.

Electrochemical testing: Constant current charge and discharge is performed for two-electrode setups at different rates based on the mass of active material (CuHcf) and a theoretical capacity of $60 \mathrm{mAh} \mathrm{g}$ ${ }^{1}$. A one-minute rest time between charge and discharge is used to allow equilibration of the electrodes. A three-electrode flooded cell setup is used for cyclic voltammetry at $1 \mathrm{mV} \mathrm{s}{ }^{-1}$ with $\mathrm{Ag} / \mathrm{AgCl}$ as the reference electrode and zinc as counter. All results shown are using $\mathrm{HD} \mathrm{Zn}$ unless mentioned otherwise. All experiments were done at $298 \mathrm{~K}$.

In situ X-ray diffraction: Synchrotron X-Ray microdiffraction was carried out by the same method as described by Gallaway et al. [21] at the Brookhaven National Laboratory. We used the X13B beam line where X-rays of wavelength $0.65 \AA$ were focused onto the working electrode of the cell to a spot size of $2 \mu \mathrm{m} \times 2 \mu \mathrm{m}$. Cell was constructed with a X-ray transparent polymer and thin walls ( $\sim 1 \mathrm{~mm}$ ) to minimize the noise to signal ratio. X-ray spectra were collected after every $1 \mathrm{~min}$.

\section{Results and Discussion}

The PBA-Zn battery cell design used in our experiments is schematically shown in Figure $\mathbf{1}$ a. A glass microscope slide acts as the platform to support the cathode, which is a conductive carbon cloth coated with CuHcf slurry (mass loading of active material $\sim 4 \mathrm{mg} \mathrm{cm}^{-2}$ ). The carbon cloth acts as a current collector and a non-woven cellulose sheet is used as a separator, which soaks up the liquid electrolyte and allows for ion exchange. Hyper-dendritic Zinc (HD Zn) plated on a sheet Zn forms the anode. The components are stacked in the order mentioned above and the assembly is placed in a cell holder 
containing the liquid electrolyte $\left(1 \mathrm{M} \mathrm{Na}_{2} \mathrm{SO}_{4} / 0.01 \mathrm{M} \mathrm{H}_{2} \mathrm{SO}_{4}\right)$. The holder is sealed to avoid loss of electrolyte via evaporation. The half cell reactions in this cell design are:

Anode: $\mathrm{Zn} \rightleftharpoons \mathrm{Zn}^{2+}+2 e^{-}$

Cathode: $\mathrm{KCu}\left[\mathrm{Fe}^{3+}(\mathrm{CN})_{6}\right]+\mathrm{x} \mathrm{Na}^{+}+\mathrm{x} \mathrm{e}^{-} \rightleftharpoons \mathrm{KNa}_{\mathrm{x}} \mathrm{Cu}\left[\mathrm{Fe}^{2+}(\mathrm{CN})_{6}\right]_{\mathrm{x}}\left[\mathrm{Fe}^{3+}(\mathrm{CN})_{6}\right]_{1-\mathrm{x}}, 0<\mathrm{x}<1$

\subsection{Copper Hexacyanoferrate as cathode}

The battery system, shown in Fig. 1a, is subjected to constant current electrochemical charge and discharge cycles at different rates. ' $\mathrm{C}$ rate' is defined as the inverse of the time, in hours, the battery would take to charge based on the theoretical capacity of CuHcf $\left(60 \mathrm{mAh} \mathrm{g}^{-1}\right)$.

Ex situ TEM micrograph and X-ray Diffractogram, shown in Fig. 1 b, c validates that the CuHcf synthesized for our experiments is identical to those reported in literature [13]. The average particle size is found to be $40 \pm 5 \mathrm{~nm}$. Recurring scan XRD is done on the active material powder, uncycled slurry electrode and fully charged cycled electrode after 250 cycles at 5C using D8 Bruker XRD. The X-ray Diffractogram of active material, shown in Fig. 1 c, is in good agreement with that of CuHcf in literature $[2,7,13,22]$. A qualitative comparison of the uncycled and cycled electrode suggests no observable change in crystal structure over 250 cycles, indicating the reversible nature and extended lifetime of $\mathrm{CuHcf}$ utilizing $\mathrm{Na}^{+}$ions. Studying the in situ XRD of the cell during operation validates this claim further.

The X13B synchrotron beamline at Brookhaven National Laboratory is used for in situ characterization of the microstructural changes in the PBA electrode over the first three cycles at 3C rate via EDXRD. The setup and procedure is the same as followed by Gallaway et al. [23] and are 
provided in the Methods section. The X-ray spectra (Figure 2 a) shows reversible shifting of the $\langle 220\rangle,\langle 400\rangle$, and $\langle 420\rangle$ peaks about the same mean $2 \theta$ values as observed in Fig. 1 c. The peak near $27^{\circ}$ is from the carbon cloth current collector and does not exhibit any peak shift during cycling. Electrochemical charge (discharge) potential corresponding to the shift in the peak position of $\langle 400>$ peak is shown in Fig. $\mathbf{2}$ b. $<400>$ has been chosen as a representative peak as it shows the highest peak shift, but similar information can be obtained from other peaks too. This shift towards a lower $2 \theta$ angle during charging (and the reverse during discharging) by $0.24^{\circ}$ indicates lattice expansion (contraction) on deintercalation (intercalation), and is consistent with the lattice changes in PBA reported in literature [24]. The lattice contraction during $\mathrm{Na}^{+}$insertion is counterintuitive, but is explained by the simultaneous addition of $\mathrm{e}^{-}$to the structure, which allows for $p i$ back-bonding and shortens the C-N bond length.

Electrochemical testing of the cell allows for analysis of the HD Zn/PBA battery performance. Experimental details of the two electrode constant current charge-discharge cycling and the three electrode cyclic voltammetry studies are provided in the Methods section. Figure 3 a shows the results of constant current charge and discharge of the cell at $5 \mathrm{C}$ rate, with a 1 min rest between each charge and discharge step. Capacity retention (Fig. $\mathbf{3}$ b), Coulombic efficiency and energy efficiency (Fig. $\mathbf{3}$ c) can be calculated using these data. The capacity retention is $90 \%$ after 300 cycles. Coulombic efficiency for each cycle is found to be $99 \%$ throughout the cycle life. This validates that there is minimal gas formation or any other irreversible reaction.

The initial energy density obtained is $103 \mathrm{Wh} \mathrm{kg}^{-1}$, which corresponds to an average specific power of $515 \mathrm{~W} \mathrm{~kg}^{-1}$. The energy efficiency is $96 \%$ in the first cycle and drops to $92 \%$ after 500 cycles. The likely cause of deviation of energy efficiency from 100\% is the I-R drop (resistive losses) in the 
electrolyte, electrode design and current collectors. This said, this ohmic drop is present at a rate of $5 \mathrm{C}$ and is not out of line with other high performance batteries at this rate.

The Coulombic and energy efficiencies illustrate high degrees of reversibility in ionic charge exchange and low overpotentials, respectively, which lead to an exceptionally high battery longevity of the $\mathrm{Zn}$ CuHcf system.

\subsection{Sodium ion rich aqueous solution as electrolyte}

The stable capacity retention of this system also relies on the fact that the majority of its capacity is due to the insertion of $\mathrm{Na}^{+}$ions into the CuHcf lattice over $\mathrm{Zn}^{2+}$ ions, which are present due to the dissolution of the $\mathrm{Zn}$ anode. There are two major factors that allow this to happen: 1) Presence of excess $\mathrm{Na}^{+}$ions. Even at the higher rates, the current range used for the experiments is much below the limiting current (corresponding to $\mathrm{Na}^{+}$ion concentration would equal zero at the electrode surface), which we estimate to be $10 \mathrm{~mA} \mathrm{~cm}$. (Details on this estimation can be found in the Supplemental Information section). As the specific capacity of Prussian Blue is $60 \mathrm{mAh} \mathrm{g}^{-1}$, a $5 \mathrm{C}$ rate is equivalent to only $300 \mathrm{~mA} \mathrm{~g}^{-1}$ (or $1.2 \mathrm{~mA} \mathrm{~cm}^{-2}$ based on the current mass loading). This suggests that our system is not $\mathrm{Na}^{+}$starved. 2) The slower kinetics of $\mathrm{Zn}^{2+}$ insertion into the cathode relative to $\mathrm{Na}^{+}$insertion kinetics $[8,25]$. Thus, in the presence of both $\mathrm{Zn}^{2+}$ and $\mathrm{Na}^{+}$ions, $\mathrm{Na}^{+}$is the dominant intercalating species. The measured capacity in Fig. 3 hence primarily reflects the cycling of $\mathrm{Na}^{+}$in CuHcf, which is known to be highly reversible. It should be noted that proton insertion is not the primary storage mechanism in PBA systems as is demonstrated in literature [26]. The corresponding cyclic voltammogram is included in the Supplemental Information section. 
Due to the fast rate $(5 \mathrm{C})$ of the galvanostatic cycling we see only one plateau and it is difficult to independently resolve the existence of multiple reactions at the electrode, corresponding to $\mathrm{Na}^{+}$and $\mathrm{Zn}^{2+}$ intercalation in CuHcf. Hence, slow scan rate cyclic voltammetry $(\mathrm{CV})$ is performed to see the effects of $\mathrm{Zn}^{2+}$ intercalation, if any. CV of the full CuHcf-Zn system in a three-electrode configuration (Figure 4 a) shows a reversible peak around $0.7 \mathrm{~V}$ vs. $\mathrm{Ag} / \mathrm{AgCl}$ reference at $1 \mathrm{mV} \mathrm{s}^{-1}$ for 200 cycles. To investigate the effect of $\mathrm{Zn}^{2+}$ in the solution, we compare the cyclic voltammogram in Fig. $\mathbf{4}$ a to two different cases: 1) Only $\mathrm{Na}^{+}$in solution with a Pt counter electrode (Fig. 4 b), and 2) only $\mathrm{Zn}^{2+}$ in solution with a Zn counter (Fig. 4 c). Peak p-p' in Fig. 4 b is a fingerprint for $\mathrm{Na}^{+}$intercalation while peaks $q-q^{\prime}$ and $r-r^{\prime}$ in Fig. $4 \mathbf{c}$ are fingerprints for $\mathrm{Zn}^{2+}$ intercalation. It is inferred qualitatively that the broadening of peak $m-m^{\prime}$ with cycling (Fig. 4 a) is due to a superposition of peaks $p-p$ ' and $q-q$ ' whereas peak $n-n$ ' corresponds to peak $r-r$ '. This indicates that using $\mathrm{Zn}$ as the anode only causes minor $\mathrm{Zn}^{2+}$ poisoning.

Also, we note that the second peak $r$ - $r$ ' of the cell operating with only $\mathrm{Zn}^{2+}$ ions in Fig. 4 c occurs at a potential of $\sim 0.9 \mathrm{~V}$ vs. $\mathrm{Ag} / \mathrm{AgCl}$. This leads to a higher energy density than that of cells operating with only $\mathrm{Na}^{+}$ions, which has only one peak $p-p$ ' at $0.6 \mathrm{~V}$, shown in Fig. 4 b.

Figure $4 \mathbf{d}$ represents the same system (only $\mathrm{Zn}^{2+}$ ions, $\mathrm{Zn}$ counter) as Fig. $\mathbf{4} \mathbf{c}$ during extended cycling. The dramatic shift in the peak positions and the transition from 2 peaks to a single peak indicates capacity fade due to a change in insertion mechanism. Recent work [11] suggests multivalent ions can intercalate into two different sites, which can account for the two peaks in the CV. Transition to one peak could be indicative of irreversible entrapment of species in one of the sites but clear understanding of this process needs further study. 
The effect of $\mathrm{Zn}$ poisoning is quantified using post cycling analysis of the PBA electrode via XPS. Peaks assignments are similar to those reported in literature. [27, 28] Figure 5 a shows the Na $1 s$ peak in the discharged state after 2 and 500 cycles; there is no Na observed in the charged state. The XPS intensity indicates that $\mathrm{Na}^{+}$continues to cycle reversibly for 500 cycles. The XPS results in Fig. $\mathbf{5} \mathbf{~ b , ~} \mathbf{c}$ focus on the $\mathrm{Zn} 2 p$ peak, and show that the concentration of $\mathrm{Zn}$ in the electrode increases with cycle number. The data also suggest that $\mathrm{Zn}^{2+}$ is present in both charged (Fig. $\mathbf{5}$ b) and discharged (Fig. $5 \mathbf{c}$ ) states, which indicates that it is not completely removed from the PBA electrode. These post cycling XPS results corroborate our previous assertion regarding the slow poisoning of PBA due to accumulation of $\mathrm{Zn}^{2+}$ in the lattice. The effect of $\mathrm{Zn}^{2+}$ over time is also reflected in the aging tests (included in the Supplemental Information section). We report that PBA vs. Zn system exhibits capacity drop with increasing storage time. Potential ways to reduce this fade include the use of a $\mathrm{Zn}$ ion blocking membrane as separator (e.g. Nafion) or the use of additives to make the electrolyte more viscous, thus inhibiting the migration of $\mathrm{Zn}$ ions to the PBA electrode.

To further bolster our analysis, we compare the capacity fade of our system in Figure 6 against other known PBA systems with varying concentrations of $\mathrm{Zn}^{2+}$. An interesting trend is observed where an increase in the $\mathrm{Zn}^{2+}$ concentration leads to a faster capacity fade. Also, as is clearly evident, the capacity retention of the battery design presented in this work (solid red line in Fig. 6) is higher than the previously reported PBA-Zn systems, and is only slightly lower than the ideal case (dashed black line in Fig. 6) when there is no Zn present in the system at all.

We conclude that using $\mathrm{Zn}^{2+}$ over $\mathrm{Na}^{+}$as the inserting species with PBA systems is a Faustian bargain, where even though initially we can extract higher energy density in the former case (as noted earlier), eventually $\mathrm{Zn}^{2+}$ increases the fade rate, resulting in a lower capacity and energy density. 


\subsection{Hyper-dendritic zinc as anode}

Hysteresis in the potential profile during cycling is proportional to the overall resistance of the cell and indicative of the kinetics of the system. Figure 7 shows the effect of replacing the sheet $\mathrm{Zn}$ with hyper-dendritic zinc (HD Zn). It is observed (Fig. 7 a) that using a HD Zn anode significantly lowers the overpotential of the charge step, during which zinc is plated on the electrode. The higher surface area of $\mathrm{HD} \mathrm{Zn}$ increases the kinetics of $\mathrm{Zn}^{2+}$ reduction, thus helping the $\mathrm{Zn}$ electrode keep up with the fast insertion kinetics of the CuHcf electrode. The discharge potential, however, is not altered. To investigate the rate capability of the system, charge and discharge profiles with HD Zn anodes at different rates are plotted in Fig. $7 \mathbf{~ b}$. The charge/discharge potential hysteresis valued measured at 1, 5, 10 and $20 \mathrm{C}$ are $0.02 \mathrm{~V}, 0.05 \mathrm{~V}, 0.07 \mathrm{~V}$ and $0.11 \mathrm{~V}$, respectively. Moreover, it can be seen in Fig. 7 c that on prolonged cycling, cells with HD Zn anodes exhibit much higher capacity retention compared to cells with sheet $\mathrm{Zn}$ anodes.

The above results clearly illustrate how the use of HD Zn can be used to battle the problem associated with dendrite formation. Our recently published work [20] shows that when starting with HD Zn (a non-equilibrium phase of zinc), the initially dendritic structure actually densifies over time. This mitigates the unwanted volume expansion and formation of sharp structures, which are the primary cause of soft shorts. Comparison of the morphological evolution of HD $\mathrm{Zn}$ and sheet $\mathrm{Zn}$ anodes over cycling is done to further validate this. In HD Zn, the grains coarsen over 100 cycles (Figure 8 a, b) and continue through 500 cycles (Fig. 8 c). This indicates that HD $\mathrm{Zn}$ evolves into a relatively less rough morphology. Sheet $\mathrm{Zn}$, on the other hand, keeps getting rougher (Fig. $8 \mathrm{~d}$, e, f) and shows dendrite-like features forming after 500 cycles. Overall, the morphology of HD Zn becomes compact with cycling, while sheet $\mathrm{Zn}$ becomes increasingly rougher. This is in agreement with the results of our previous work.[20] 
In essence, the use of $\mathrm{HD} \mathrm{Zn}$ as an anode results in greater cycling stability with faster reaction kinetics. The high surface area of HD Zn electrodes does raise a concern of higher hydrogen gas formation. However, as noted from Fig. 3 c, despite the use of HD Zn electrodes, a 99\% Coulombic efficiency is achieved, indicating minimal gas formation.

\section{Conclusions}

In this work, we cycle CuHcf (coated onto carbon cloth) against a $\mathrm{HD} \mathrm{Zn}$ anode in an acidic $\mathrm{Na}_{2} \mathrm{SO}_{4}$ solution. Unlike in traditional PBA-Zn systems, which use $\mathrm{Zn}^{2+}$ as the intercalating species and have low cycle lifetimes, we introduce $\mathrm{Na}^{+}$as the primary ion for charge transport to achieve a cycling life of over 500 cycles. This is five times greater than any PBA-Zn system reported in literature, despite the inevitable presence of $\mathrm{Zn}^{2+}$ in our system due to dissolution of the anode.

Two primary factors that lead to a reduced cycle life in traditional CuHcf-Zn batteries are addressed by our dual-ion system: $i$ ) As shown by in situ EDXRD, $\mathrm{Na}^{+}$intercalates reversibly into the open cage crystal structure of CuHcf. We demonstrate that $\mathrm{Na}^{+}$ions preferentially intercalate in PBA over $\mathrm{Zn}^{2+}$ ions, resulting in a reduced degree of zinc poisoning, even with a $\mathrm{Zn}$ anode. ii) The gradual degradation in cell capacity typically observed with conventional sheet $\mathrm{Zn}$ anodes is greatly mitigated by the use of HD Zn instead. We believe this is due to fewer incidences of soft shorts and delayed passivation in the latter case, though further investigation is warranted.

In all, by combining the use of a $\mathrm{Na}^{+}$-dominant system and a highly dendritic $\mathrm{Zn}$ anode, we achieved greatly-enhanced cyclability in CuHcf-Zn compared to traditional systems, observing $<10 \%$ drop in cell capacity over 300 cycles. 


\section{Acknowledgements}

The authors gratefully acknowledge grants NSF CMMI 1402872, NSF DMR 1156422, NSF IGERT 0903661 and the XEROX UAC award for student support, and the DOE NSLS Beamline X13 for characterization of the structure in situ. We also thank Clark Chen for helping us gather XPS data. 


\section{References}

[1]. K. Itaya, I. Uchida, V.D. Neff, Electrochemistry of polynuclear transition metal cyanides: Prussian blue and its analogues, Acc. Chem. Res. 19 (1986) 162-168.

[2]. Y. Lu, L. Wang, J. Cheng, J.B. Goodenough, Prussian blue: a new framework of electrode materials for sodium batteries, Chem. Commun. . 48 (2012) 6544-6546.

[3]. L.M. Siperko, T. Kuwana, Electrochemical and Spectroscopic Studies of Metal Hexacyanometalate Films: I . Cupric Hexacyanoferrate, J. Electrochem. Soc. 130 (1983) 396402.

[4]. V.D. Neff, Electrochemical Oxidation and Reduction of Thin Films of Prussian Blue, J. Electrochem. Soc. 125 (1978) 886-887.

[5]. T. Matsuda, Y. Moritomo, Thin Film Electrode of Prussian Blue Analogue for Li-ion Battery, Appl. Phys. Express. 4 (2011) 047101.

[6]. C.D. Wessells, M.T. McDowell, S.V. Peddada, M. Pasta, R.A. Huggins, Y. Cui, Tunable reaction potentials in open framework nanoparticle battery electrodes for grid-scale energy storage, ACS Nano. 6 (2012) 1688-1694.

[7]. M. Pasta, C.D. Wessells, R.A. Huggins, Y. Cui, A high-rate and long cycle life aqueous electrolyte battery for grid-scale energy storage, Nat. Commun. 3 (2012) 1149.

[8]. _L. Zhang, L. Chen, X. Zhou, Z. Liu, Towards High-Voltage Aqueous Metal-Ion Batteries Beyond 1.5 V: The Zinc/Zinc Hexacyanoferrate System, Advanced Energy Materials. (2014).

[9]. Z. Jia, B. Wang, Y. Wang, Copper hexacyanoferrate with a well-defined open framework as a positive electrode for aqueous zinc ion batteries, Mater. Chem. Phys. 149-150 (2015) 601-606.

[10]. R. Trócoli, F. La Mantia, An aqueous zinc-ion battery based on copper hexacyanoferrate, ChemSusChem. 8 (2015) 481-485. 
[11]. R.Y. Wang, B. Shyam, K.H. Stone, J.N. Weker, M. Pasta, H.-W. Lee, et al., Reversible Multivalent (Monovalent, Divalent, Trivalent) Ion Insertion in Open Framework Materials, Adv. Energy Mater. (2015).

[12]. C.D. Wessells, S.V. Peddada, R.A. Huggins, Y. Cui, Nickel hexacyanoferrate nanoparticle electrodes for aqueous sodium and potassium ion batteries, Nano Lett. 11 (2011) 5421-5425.

[13]. C.D. Wessells, R.A. Huggins, Y. Cui, Copper hexacyanoferrate battery electrodes with long cycle life and high power, Nat. Commun. 2 (2011) 550.

[14]. A.B. Bocarsly, S. Sinha, Effects of surface structure on electrode charge transfer properties: Induction of ion selectivity at the chemically derivatized interface, J. Electroanal. Chem. Interfacial Electrochem. 140 (1982) 167-172.

[15]. C.C. Yang, S.J. Lin, Improvement of high-rate capability of alkaline Zn-MnO 2 battery, J. Power Sources. (2002).

[16]. J.T. Kim, J. Jorné, The Kinetics and Mass Transfer of Zinc Electrode in Acidic Zinc- Chloride Solution, J. Electrochem. Soc. 127 (1980) 8-15.

[17]. A.R. Despic, J. Diggle, J.O. Bockris, Mechanism of the Formation of Zinc Dendrites, J. Electrochem. Soc. 115 (1968) 507-508.

[18]. C. Cachet, B. Saïdani, R. Wiart, The Behavior of Zinc Electrode in Alkaline Electrolytes: I . A Kinetic Analysis of Cathodic Deposition, J. Electrochem. Soc. 138 (1991) 678-687.

[19]. R.V. Moshtev, P. Zlatilova, Kinetics of growth of zinc dendrite precursors in zincate solutions, J. Appl. Electrochem. 8 (1978) 213-222.

[20]. M. Chamoun, B.J. Hertzberg, T. Gupta, D. Davies, S. Bhadra, B. Van Tassell, et al., Hyperdendritic nanoporous zinc foam anodes, NPG Asia Materials. 7 (2015) e178. 
[21]. J.W. Gallaway, A.M. Gaikwad, B. Hertzberg, C.K. Erdonmez, Y.-C.K. Chen-Wiegart, L.A. Sviridov, et al., An In Situ Synchrotron Study of Zinc Anode Planarization by a Bismuth Additive, J. Electrochem. Soc. 161 (2014) A275-A284.

[22]. R. Rigamonti, Structure of Cupriferrocyanides I. Copper Ferrocyanide and Potassium Copper Ferrocyanide, Gazz. Chim. Ital. (1937).

[23]. J.W. Gallaway, C.K. Erdonmez, Z. Zhong, M. Croft, L.A. Sviridov, T.Z. Sholklapper, et al., Real-time materials evolution visualized within intact cycling alkaline batteries, J. Mater. Chem. A Mater. Energy Sustain. 2 (2014) 2757-2764.

[24]. Dostal, G. Kauschka, S.J. Reddy, F. Scholz, Lattice contractions and expansions accompanying the electrochemical conversions of Prussian blue and the reversible and irreversible insertion of rubidium and thallium ions, J. Electroanal. Chem. . 406 (1996) 155-163.

[25]. S. Kawamura, H. Kuraku, K. Kurotaki, The composition and ion-exchange behavior of zinc hexacyanoferrate(II) analogues, Anal. Chim. Acta. 49 (1970) 317-322.

[26]. R.Y. Wang, C.D. Wessells, R.A. Huggins, Y. Cui, Highly reversible open framework nanoscale electrodes for divalent ion batteries, Nano Lett. 13 (2013) 5748-5752.

[27]. A. Mekki, D. Holland, C.F. McConville, M. Salim, An XPS study of iron sodium silicate glass surfaces, J. Non-Cryst. Solids. 208 (1996) 267-276.

[28]. N. Gogurla, A.K. Sinha, S. Santra, S. Manna, S.K. Ray, Multifunctional Au-ZnO plasmonic nanostructures for enhanced UV photodetector and room temperature NO sensing devices, Sci. Rep. 4 (2014) 6483. 


\section{Figure Captions}

Figure 1. Cell Schematic and validation of synthesized materials. (a) Schematic of 2-electrode cell design (b) TEM image of CuHcf powder showing particle size, (c) X-ray Diffractogram from CuHcf in literature [20], and observed data for CuHcf powder, CuHcf electrodes both uncycled and after 250 cycles. Peak assignment is done based on a previous study [13]. (d) SEM images of PBA on carbon cloth

Figure 2. In situ EDXRD analysis of PBA during cycling. (a) Synchrotron based in situ XRD spectra for three charge-discharge cycles at 3C rate. Each line on the plot corresponds to the X-ray spectra at a particular state of charge, with the blue and red lines indicating completely charged and completely discharged states, respectively. (b) (Top) the electrochemical data of potential vs. time during X-ray imaging. (Bottom) Peak position of <400> corresponding to plot (a).

Figure 3. Electrochemical characterization of the two-electrode cell at 5C. (a) 500 cycles of charge and discharge between 1.4 and $2.1 \mathrm{~V}$ vs. Zn. (b) Capacity and fractional capacity retention vs. cycle number for charge and discharge. (c) Energy efficiency and Coulombic efficiency vs. cycle number. Electrolyte used is $1 \mathrm{M} \mathrm{Na}_{2} \mathrm{SO}_{4} / 0.01 \mathrm{M} \mathrm{H}_{2} \mathrm{SO}_{4}$.

Figure 4. Cyclic Voltammetry of CuHcf in different electrolytes. Cyclic Voltammetry at $1 \mathrm{mV} \mathrm{s}^{-1}$ in a flooded cell design with $\mathrm{Ag} / \mathrm{AgCl}$ as reference for (a) CuHcf vs. $\mathrm{Zn}$ in $1 \mathrm{M} \mathrm{Na}_{2} \mathrm{SO}_{4} / 0.01 \mathrm{M}$ $\mathrm{H}_{2} \mathrm{SO}_{4}$ for cycle 1 (green) to cycle 200 (red); (b) CuHcf vs. Pt in $1 \mathrm{M} \mathrm{Na}_{2} \mathrm{SO}_{4} / 0.01 \mathrm{M} \mathrm{H}_{2} \mathrm{SO}_{4}$ for cycle 1 (green) to cycle 50 (red); (c) CuHcf vs. $\mathrm{Zn}$ in $1 \mathrm{M} \mathrm{ZnSO}_{4} / 0.01 \mathrm{M} \mathrm{H}_{2} \mathrm{SO}_{4}$. for cycle 1 (green) to cycle 50 (red); (d) CuHcf vs. $\mathrm{Zn}$ in $1 \mathrm{M} \mathrm{ZnSO}_{4} / 0.01 \mathrm{M} \mathrm{H}_{2} \mathrm{SO}_{4}$ for cycle 1 (green) to cycle 200 (red).

Figure 5. XPS of PBA electrode showing Na and Zn. (a) $\mathrm{Na} 1 \mathrm{~s}$ peak in discharged state after 2 
cycles (blue) and after 500 cycles (red). Zn 2p peak changing as a function of cycle no. in PBA electrode in (b) Charged state, (c) Discharged state

Figure 6. Capacity retention of various PBA vs. Zn systems. \% Capacity retention of the following systems is compared; dashed lines are data reproduced from literature, solid lines represent our experimental data. $i$. CuHcf vs. $\mathrm{NiHcf}_{\text {in }} \mathrm{NaNO}_{3}$ at $8.3 \mathrm{C}$ [6], ii CuHcf vs. $\mathrm{Zn}$ in $\mathrm{Na}_{2} \mathrm{SO}_{4}$ at $5 \mathrm{C}$ (present work), iii $\mathrm{CuHcf}$ vs. $\mathrm{Zn}$ in $\mathrm{ZnSO}_{4}$ at $10 \mathrm{C}$ [10], iv CuHcf vs. $\mathrm{Zn}$ in $\mathrm{Na}_{2} \mathrm{SO}_{4} / \mathrm{ZnSO}_{4}$ at $5 \mathrm{C}$ (present work), v. CuHcf vs. $\mathrm{Zn}$ in $\mathrm{ZnSO}_{4}$ at $5 \mathrm{C}$ (present work), vi. $\mathrm{ZnHcf}$ vs. $\mathrm{Zn}$ in $\mathrm{ZnSO}_{4}$ at $5 \mathrm{C}$ [8]. The solid grey arrow represents the direction of increase of $\mathrm{Zn}^{2+}$ ion concentration in the electrolyte.

Figure 7. Electrochemical analysis of anodic HD Zn. (a) Effect of using HD Zn compared to Zn sheet as an anode on charge and discharge profiles of cycle 2 at $5 \mathrm{C}$ rate. (b) Constant current charge and discharge at $1 \mathrm{C}, 5 \mathrm{C}, 10 \mathrm{C}, 20 \mathrm{C}$ and $50 \mathrm{C}$ for $\mathrm{HD} \mathrm{Zn}$. Cycling is done at $5 \mathrm{C}$ rate for cycle 2. (c) Fractional capacity vs. cycle number compared for sheet $\mathrm{Zn}$ and $\mathrm{HD} \mathrm{Zn}$ at $5 \mathrm{C}$ rate. Electrolyte used is $1 \mathrm{M} \mathrm{Na}_{2} \mathrm{SO}_{4} / 0.01 \mathrm{M} \mathrm{H}_{2} \mathrm{SO}_{4}$.

Figure 8. Evolution of Zn morphology with cycles. HD Zn after (a) 0 cycles, (b) 100 cycles, (c) 500 cycles. Sheet Zn after (d) 0 cycles, (e) 100 cycles, (f) 500 cycles. Constant current cycling was done at 5C rate based on PBA active mass. Post cycling, zinc electrodes were washed in DI water and dried in a vacuum desiccator overnight. 
(a)

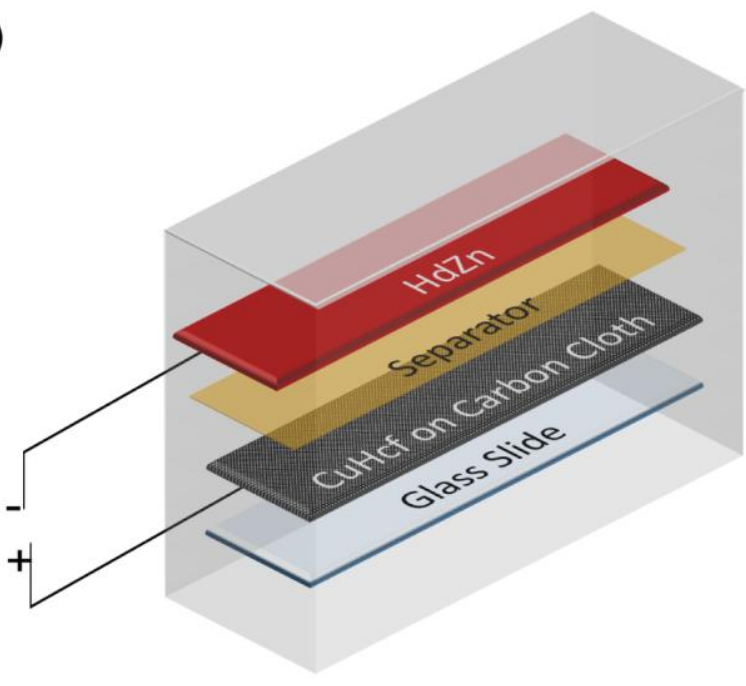

(c)

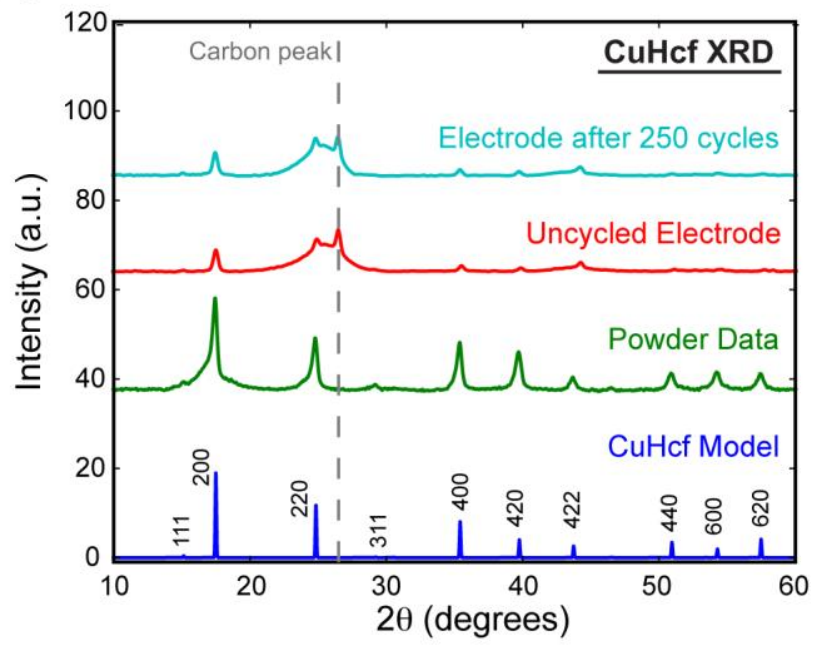

(b)

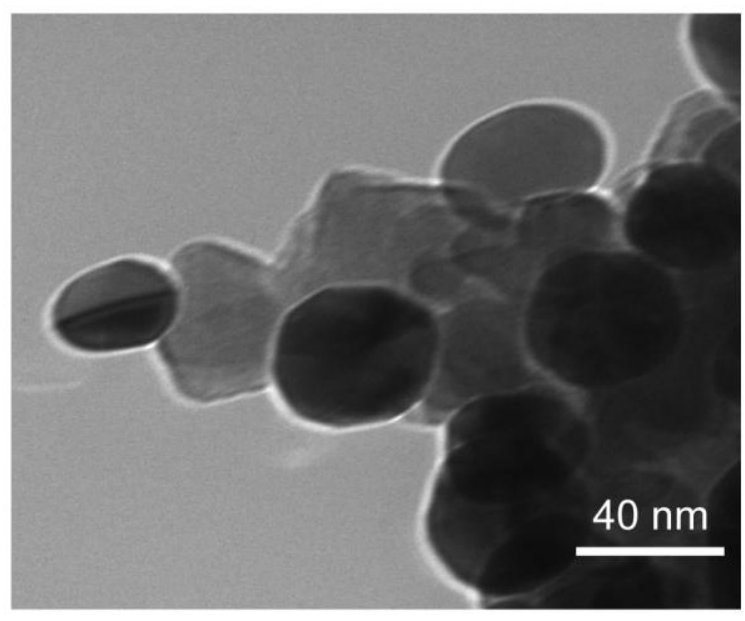

(d)

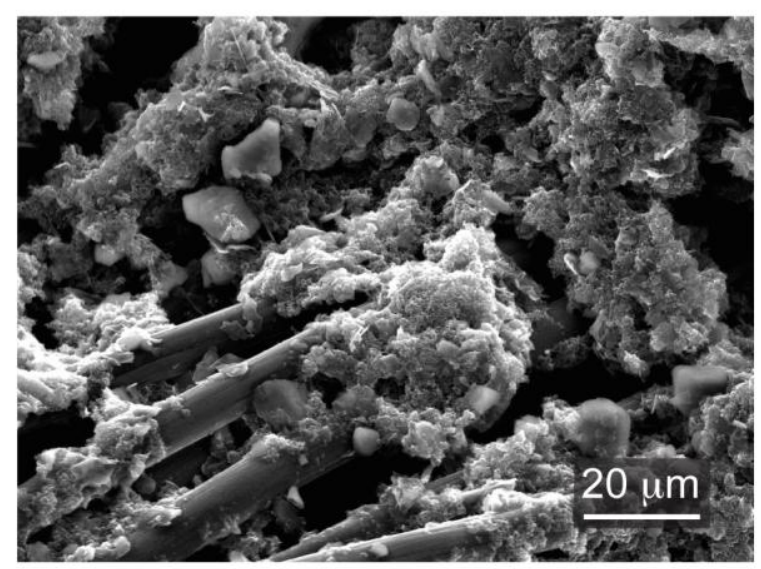

Figure 1 
(a)

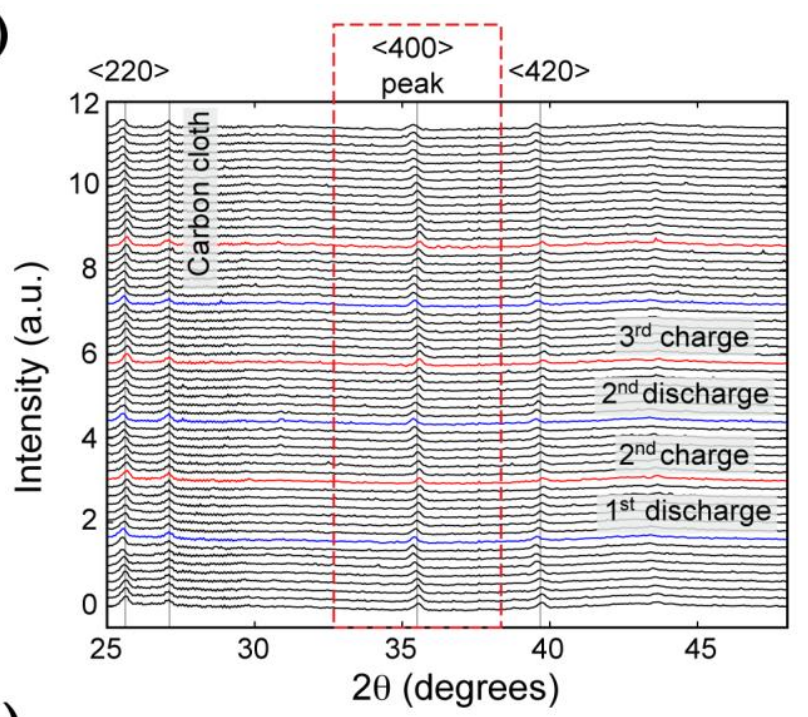

(b)

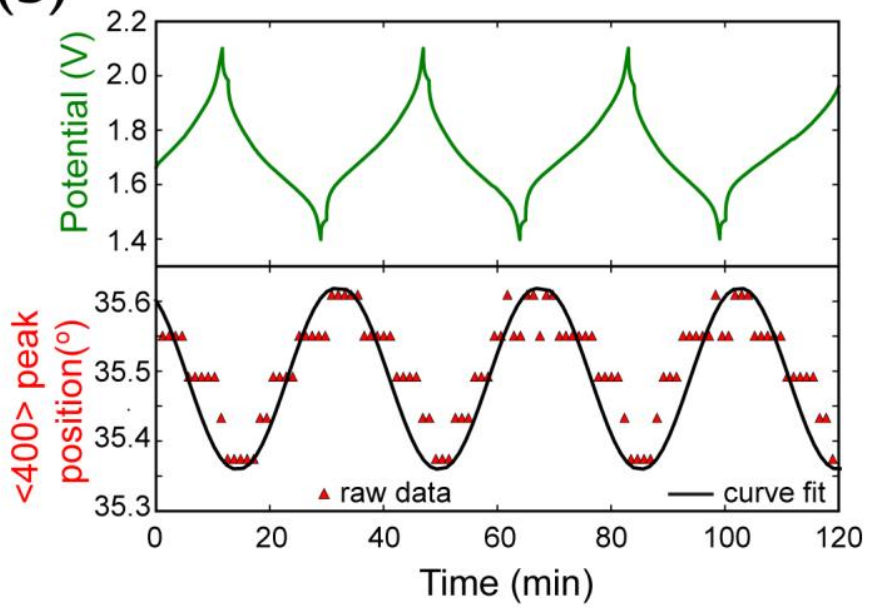

Figure 2 
(a)

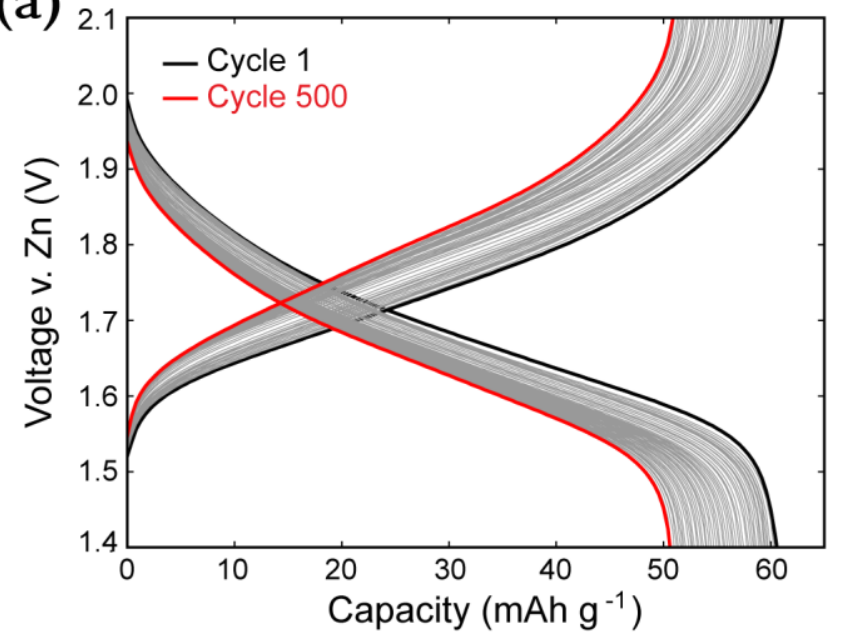

(b)

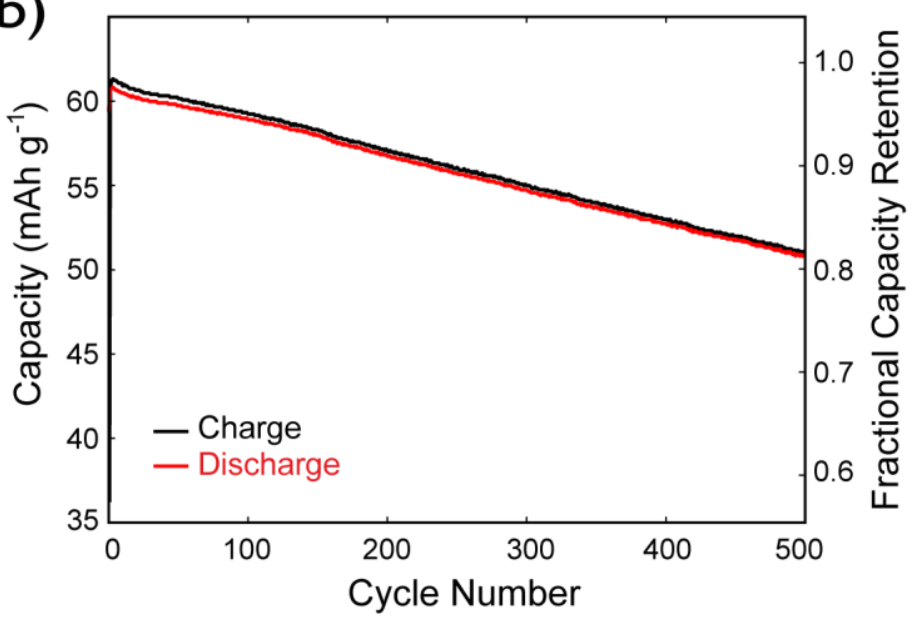

(c)

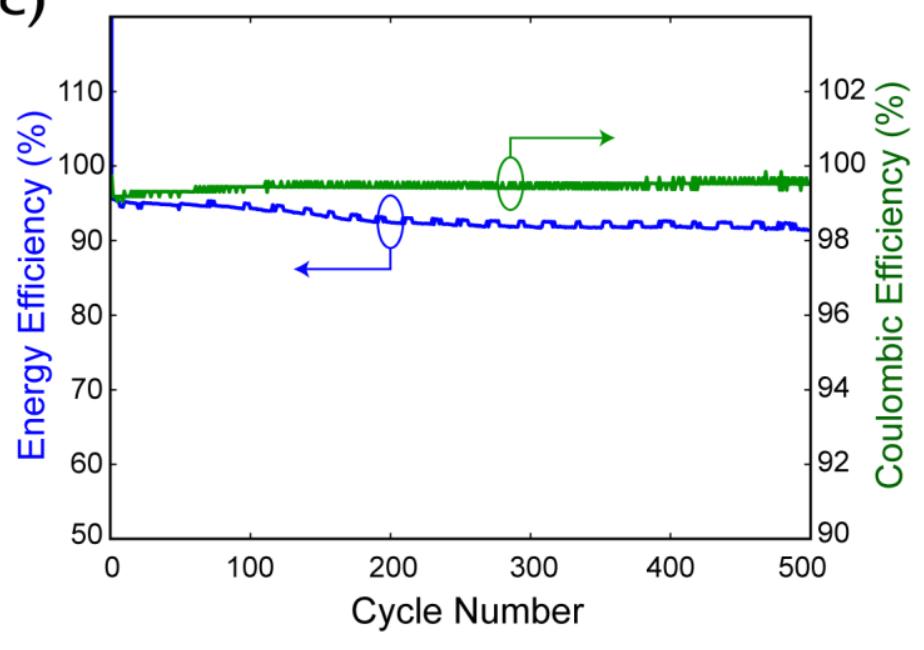

Figure 3 
(a)

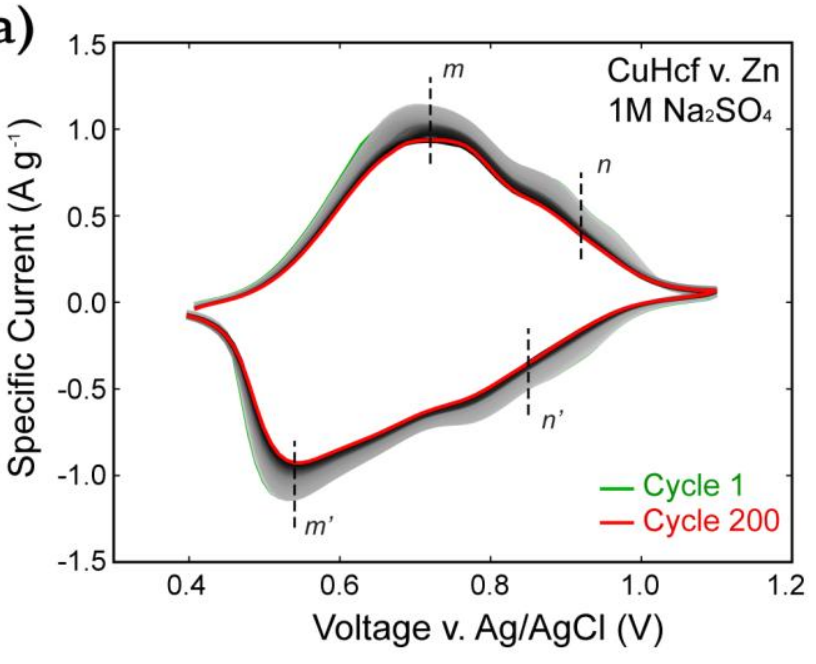

(c)

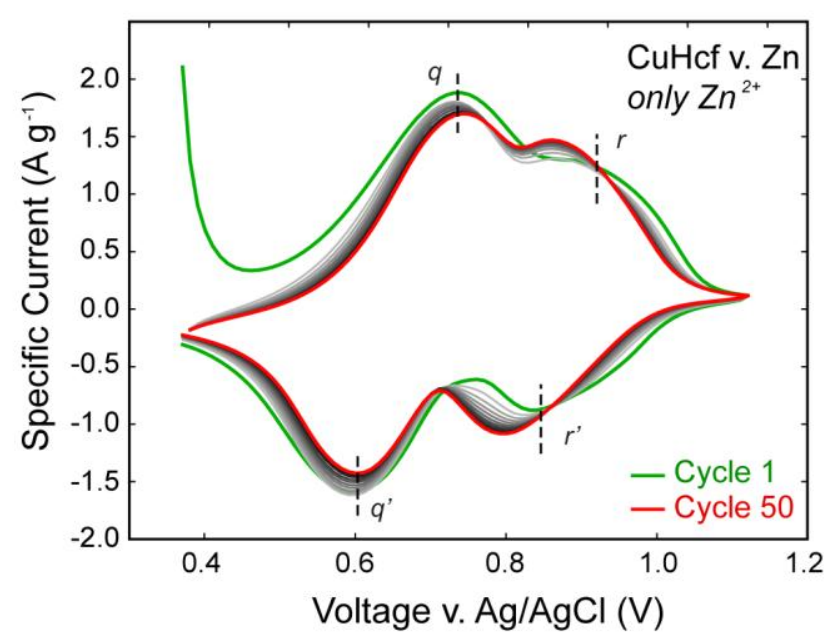

(b)

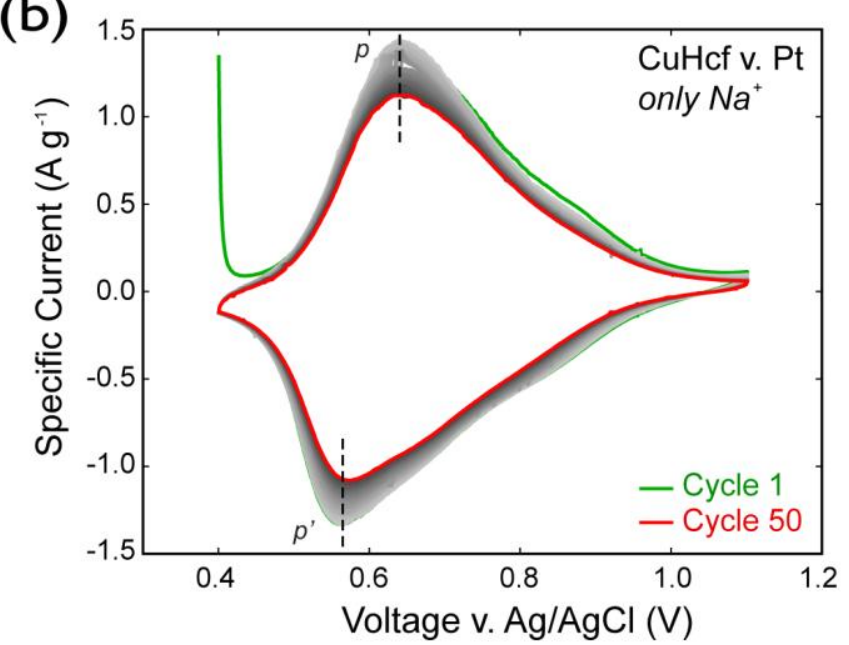

(d)

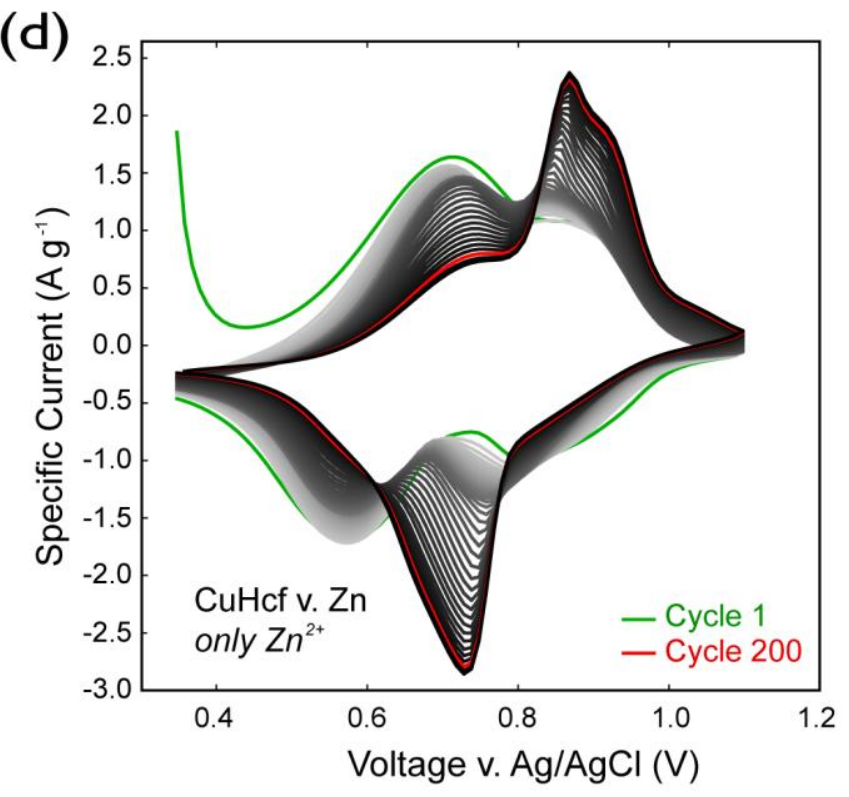

Figure 4 
(a)

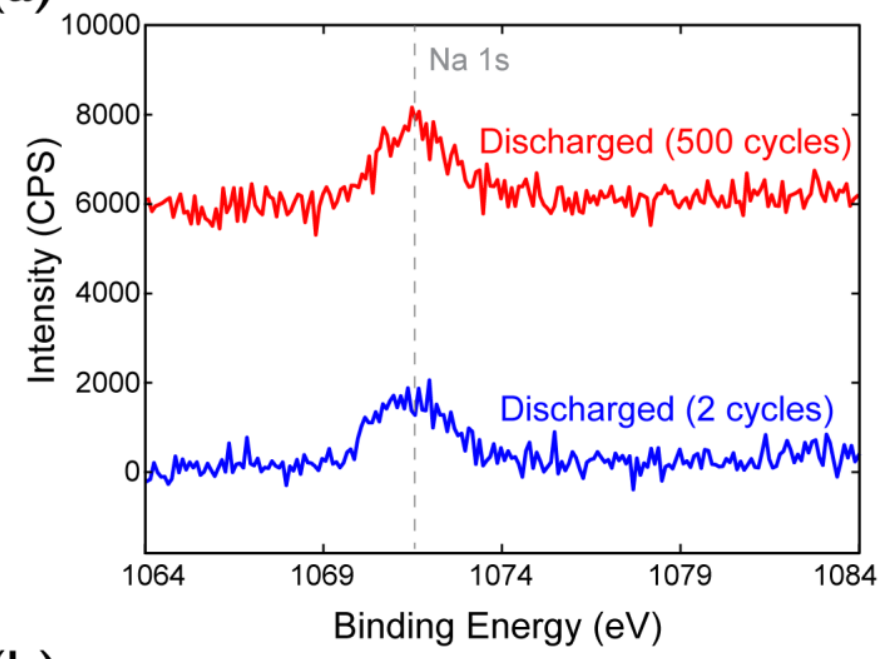

(b)

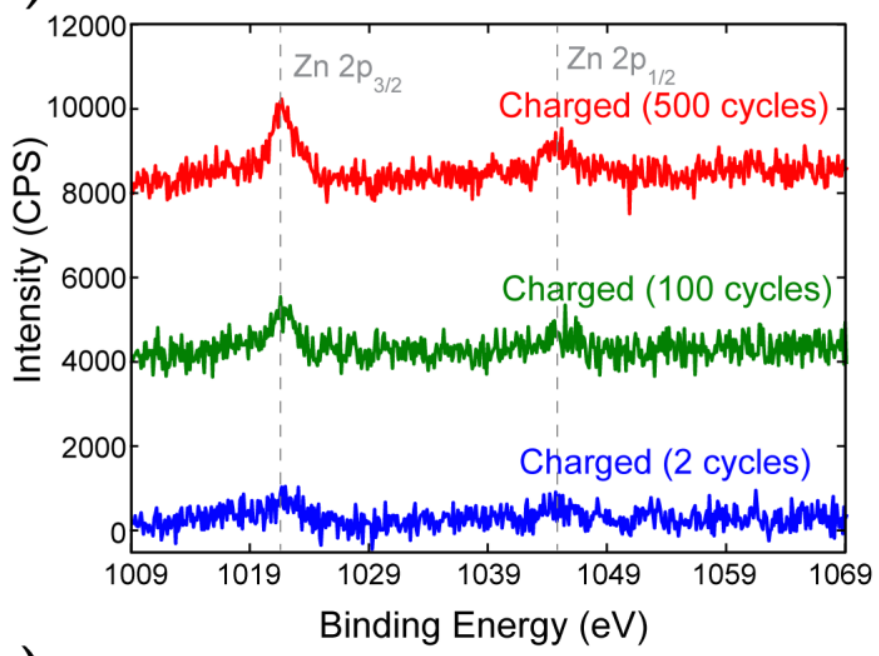

(c)

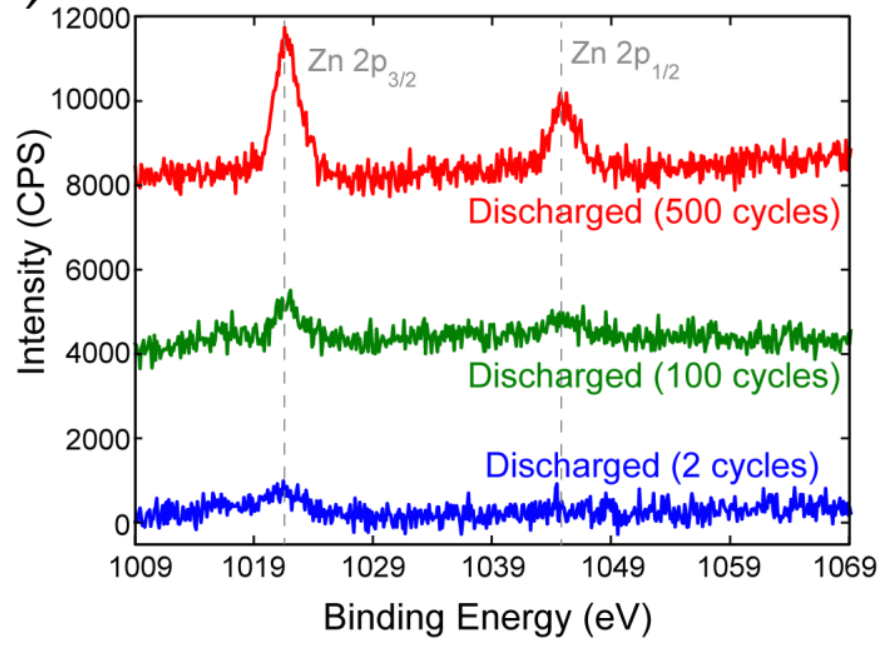

Figure 5 


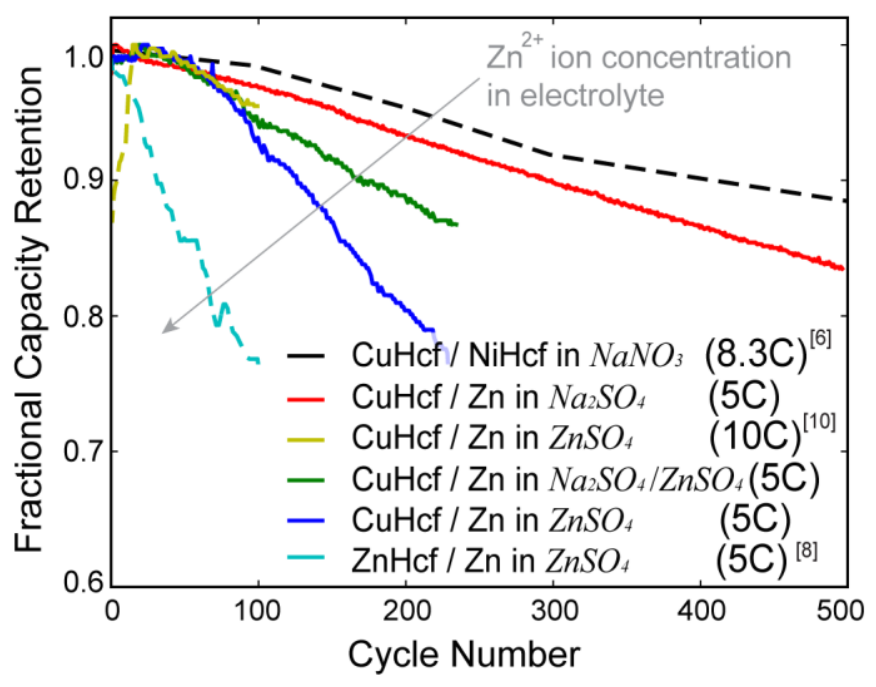

Figure 6 
(a)

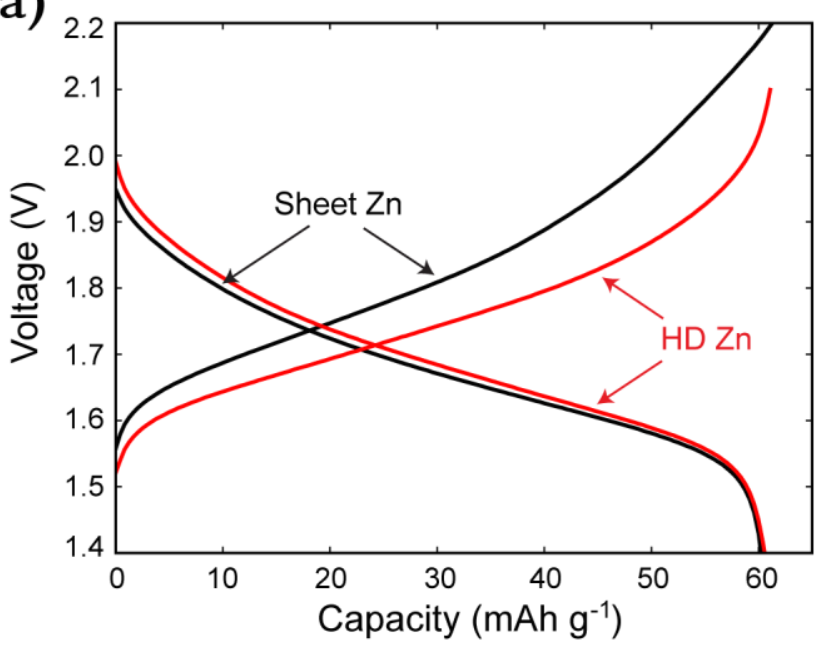

(b)

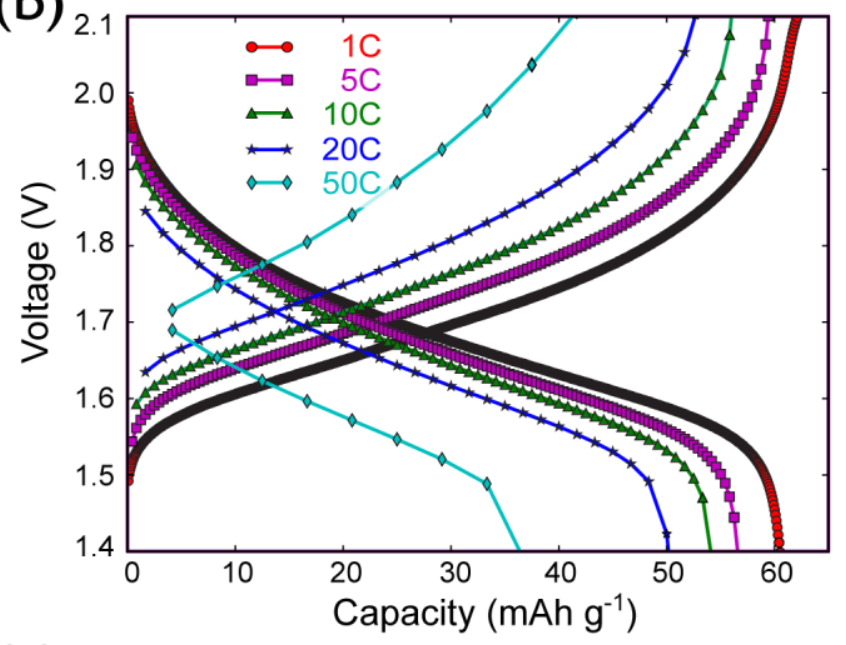

(c)

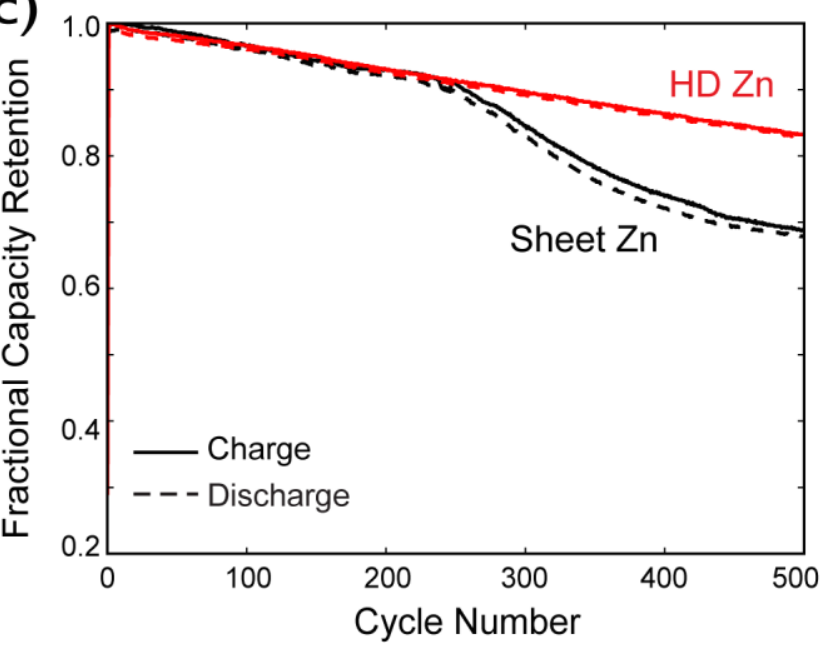

Figure 7 

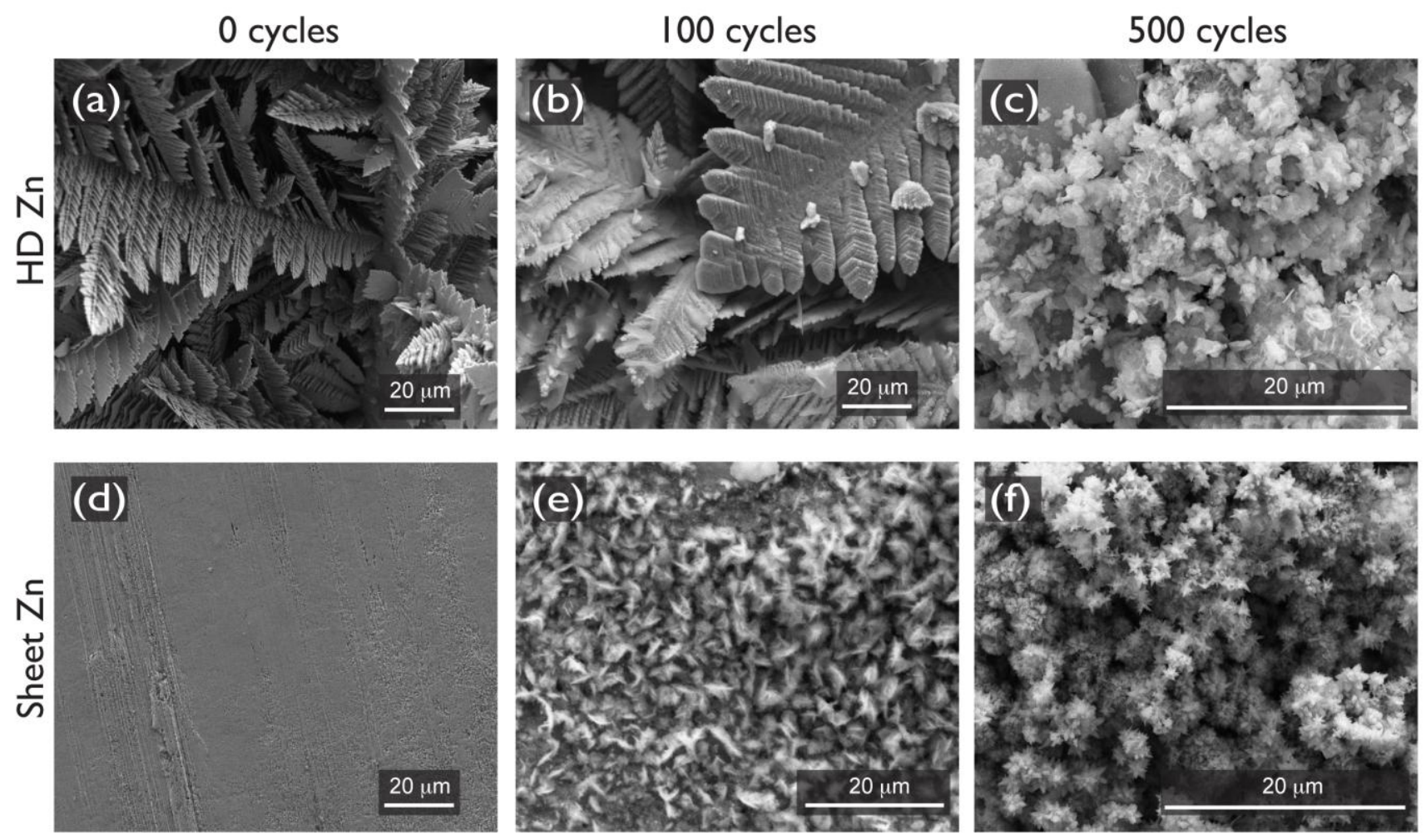

Figure 8 